\title{
OS ESTUDOS DE GÊNERO NA EDUCAÇÃO: ANÁLISE DO DISCURSO DE QUATRO DOCUMENTOS OFICIAIS
}

\section{GENDER STUDIES IN EDUCATION: ANALYSIS OF THE SPEECH OF FOUR OFFICIAL DOCUMENTS}

\author{
Demóstenes Dantas Vieira ${ }^{1}$ \\ Efraim de Alcântara Matos ${ }^{2}$ \\ Antônio Soares Júnior da Silva ${ }^{3}$
}

Doi: 10.36066/compcs.v1i23.7191

\begin{abstract}
Resumo: Este trabalho propõe uma investigação documental acerca da discussão de gênero e educação profissional nos documentos oficiais, mais especificamente, na Lei de Diretrizes e Bases da Educação Nacional LDB (1996), no Plano Nacional de Educação - PNE (2001 - 2010), no Plano Nacional de Educação - PNE (2011 - 2020) e nas Diretrizes Curriculares Nacionais para Educação Profissional Técnica de Nível Médio DCNEPTNM (2012). Em vista disso, propomos investigar os discursos acerca das concepções de gênero materializadas no texto. Para tanto, adotamos como suporte teórico-metodológico a Análise do Discurso de linha pecheutiana e a Linguística Queer, principalmente, as contribuições de Butler (2003), Borba (2015), Bourdieu (2003), Katz (1996) e Pêcheux (1995/1997). Os resultados apontam para três formas de referenciação aos estudos de gênero. A primeira constitui-se de um breve apagamento da discussão, substituído por uma referência camuflada e, por fim, por um desvelamento da discussão.
\end{abstract}

Palavras-chave: Discurso, gênero, educação profissional, documentos oficiais.

\begin{abstract}
This work is a documentary research on business discussion and professional information in official documents, more specifically, Lei de Diretrizes e Bases da Educação Nacional - LDB (1996), no Plano Nacional de Educação - PNE (2001 - 2010), no Plano Nacional de Educação - PNE (2011 - 2020) e nas Diretrizes Curriculares Nacionais para Educação Profissional Técnica de Nível Médio - DCNEPTNM (2012). In view of this, we propose to investigate the discourses about the conceptions of gender materialized in the text. Therefore, we adopted as theoretical-methodological support the Analysis of the pheheutian Speech Discourse and Queer Linguistics, mainly, the contributions of Butler (2003), Borba (2015), Bourdieu (2003), Katz (1996) e Pêcheux $(1995 / 1997)$. The results point to three forms of reference to gender studies. The first is a brief erasure of the discussion, replaced by a camouflaged reference, and finally by an unveiling of the discussion.
\end{abstract}

Keywords: Discourse, gender, professional education, official documents.

\section{INTRODUÇÃO}

Este trabalho propõe a análise do discurso da Lei de Diretrizes e Bases da Educação Nacional - LDB (1996) e do Plano Nacional de Educação (2001) acerca da discussão de gênero. Para tanto, adotamos como aporte teórico-metodológico a Análise do Discurso da

\footnotetext{
${ }^{1}$ Doutorando em Letras pela Universidade Federal do Pernambuco - UFPE; Professor do Instituto Federal de Educação, Ciência e Tecnologia do Rio Grande do Norte - IFRN. E-mail: demostenes.vieira@ifrn.edu.br.

${ }^{2}$ Mestre em Matemática pela Universidade Federal Rural do Semi-Árido - UFERSA; Professor do Instituto Federal de Educação, Ciência e Tecnologia do Rio Grande do Norte - IFRN. E-mail: efraimmat@gmail.com.

${ }^{3}$ Aluno do Programa de Pós-Graduação em Educação Profissional e Tecnológica - PROFEPT, oferecido pelo Instituto Federal Sul-rio-grandense - IFSUL. E-mail: antoniojunioredu@yahoo.com.br.

Compocs, v1, n 23 - jul -dez 2020
} 
linha pecheutiana e a linguística queer, principalmente, as contribuições de Butler (2003), Borba (2015), Bourdieu (2003), Katz (1996), Pêcheux (1995/1997), dentre outros.

Esta pesquisa justifica-se pela atualidade das discussões acerca dos Estudos de Gênero em educação, tendo em vista o crescente conservadorismo que tem se instalado no país que caminha para uma tentativa de marginalização dos estudos acerca da identidade de gênero e educação sexual nas escolas. Vale salientar que esse artigo é um recorte de uma pesquisa maior que propõe realizar uma genealogia acerca das concepções de gênero nos documentos oficiais desde a LDB até o Plano Nacional da Educação (2011-2020), perpassando a discussão acerca do projeto de lei Escola sem Partido.

Os resultados iniciais apontam para o aprimoramento da discussão acerca da diversidade sexual e identidade de gênero, da LDB (1996) ao Plano Nacional de Educação PNE (2001), evoluindo de um breve apagamento na LDB até o aprofundamento da discussão no Plano Nacional de Educação - PNE proposto para decênio 2001 a 2010 e para o decênio 2011 a 2020. Em vista disso, a próxima etapa desse trabalho é análise do Projeto Escola sem Partido e os impactos de sua aprovação nas discussões acerca da identidade de gênero e educação sexual nas escolas.

\section{CONSIDERAÇÕES SOBRE A ANÁLISE DO DISCURSO}

Embora diversos filósofos e pesquisadores tenham contribuído para os Estudos do Discurso, é somente na década de 60, com os estudos de Michel Pêcheux, que a Análise do Discurso (doravante AD) se consolida como uma disciplina, constituindo-se a partir de questões de três áreas de conhecimento: da Linguística, do Marxismo e da Psicanálise. À vista disso, é comum entre os pesquisadores a acepção de que a $\mathrm{AD}$ se configura como uma disciplina de entremeio (ORLANDI, 2005), tendo se constituído a partir de uma episteme entre diferentes áreas do conhecimento.

A proposta teórico-epistemológica de Pêcheux (1969) traz à baila a articulação dos três domínios (a saber, a Linguística, o Marxismo e a Teoria do Discurso) perpassados por uma teoria não-subjetiva da subjetividade, evidentemente, de base psicanalítica. Articulando essas três áreas de conhecimento, Pêcheux dá início não só a uma nova abordagem aos estudos da linguagem, mas também a uma nova concepção de ideologia, principalmente, no que concerne a um espaço intervalar entre linguagem, ideologia e sujeito. 
Nesse sentido, a AD surge em oposição às concepções de ideologia recorrente nas Ciências Sociais e de língua/linguagem na Linguística, concepções predominantes em seu tempo. Assim, Pêcheux formula a Análise Automática do Discurso (1969) propondo uma análise que se contrapõe a uma ciência da linguagem centrada no abismo entre a estrutura e o sujeito, entre práticas de linguagem e prática política. Para ele, a transparência da linguagem é um mito, sendo necessário investigarmos as ideologias que perpassam as práticas linguísticas, o próprio sujeito e as redes de interação social. Tratava-se, portanto, de estabelecer a relação entre língua, ideologia e sujeito. Logo, postula-se um novo objeto de estudo, o discurso. Nesse sentido, o discurso apresenta-se como "objeto sócio histórico em que o linguístico intervém como pressuposto" (ORLANDI , 2005, p. 15-16).

Nesse sentido, pode-se dizer que o discurso materializa-se na língua, enquanto a ideologia no discurso. Para Orlandi (2002, p.17), "não há discurso sem sujeito e não há sujeito sem ideologia: o indivíduo é interpelado em sujeito pela ideologia e é assim que a língua faz sentido".

Nesse sentido, as noções de assujeitamento e interpelação nos levam a uma concepção de análise em que o interesse na região do materialismo histórico "é a da superestrutura ideológica em sua ligação com o modo de produção que domina a formação social considerada" (PÊCHEUX, 1997, p. 165). Pêcheux nos leva ao entendimento que a superestrutura ideológica não é somente expressão da base econômica, embora esteja interpelada por ela. Desse modo, "a região da ideologia deve ser caracterizada por uma materialidade específica articulada sobre a materialidade econômica" (PÊCHEUX, 1997, p. $165)$.

Já tendo apresentado as contribuições do Marxismo, vale fazer algumas considerações sobre como a psicanálise subsidiou a formulação de uma teoria não subjetiva da subjetividade. Na obra Semântica e Discurso, (1995, p. 133), Pêcheux retoma Lacan nas assertivas sobre o inconsciente, no sentido de que "o inconsciente é o discurso do Outro". Nesse sentido, "o sujeito só é sujeito por seu assujeitamento ao campo do Outro, o sujeito provém de seu assujeitamento sincrônico a esse campo" (PÊCHEUX, 1995, p. 183).

Dessa forma a $\mathrm{AD}$ desliza e/ou expande o objeto de estudo da linguística, trazendo à baila a importância da enunciação e, portanto, dos elementos extralinguísticos, embora também ressignifique o modelo elaborado por Benveniste - emissor, código, e receptor embora, na $\mathrm{AD}$, não possamos falar da comunicação como um modelo tão fechado assim. Nesse sentido, a enunciação para a AD, extrapola os limites de uma concepção de linguagem como instrumento de comunicação (concepção saussuriana) e/ou como expressão de 
pensamento (concepção clássica também presente em Benveniste). A AD desloca a noção de sentido único e traz à baila o discurso como "efeitos de sentido", tendo em vista a concepção de sujeito dividido, constituído por outros discursos e, consequentemente, de um sujeito que ocupa posições sociohistóricas diferentes, podendo, portanto, produzir sentidos diferentes com o mesmo enunciado.

\section{A LINGUÍSTICA QUEER E AS CONCEPÇÕES DE GÊNERO - BREVES CONSIDERAÇÕES}

A Linguística Queer deve ser compreendida como "estudo crítico da heteronormatividade a partir de um ponto de vista linguístico" (MOTSCHENBACHER, 2011, p. 150). Ela segue o princípio de que as identidades sexuais são fragmentadas, não essencialistas e mutáveis, propondo que elas não advêm de uma realidade pré-discursiva, pelo contrário, emergem de contextos sociais, políticos e culturais, e "só podem ser entendidas como produtos/efeitos de performances corporais e linguísticas que repetem, reiteram ou subvertem discursos dominantes que trancafiam as posições de sujeito em binarismos, como homem/mulher, hétero/homo" (BORBA, 2015, p. 91). De certa forma, ela é um desdobramento da Teoria Queer e bebe em seus fundamentos teóricos.

Nesse sentido, a Linguística Queer propõe uma análise crítica sobre os discursos acerca da heteronormatividade e das identidades marginalizadas, não normativas. Por conseguinte, o conceito de gênero deve ser entendido "como uma sofisticada maquinaria discursiva mantida por instituições como o direito, a medicina, a família, a escola, e a língua, que produzem corpos-machos e corpos-fêmeas, obscurecendo outras possibilidades de estruturação das práticas generificadas e sexuais” (BORBA, 2015, p. 96).

À vista disso, ela deve ser entendida a partir de dispositivos que produzem regras que disciplinam as práticas sexuais e que devem ser reproduzidas e constantemente reiteradas para que assumam efeito substancial, moral, com efeito natural e centralizador. Conforme escreve Butler (2003, p. 157), "as normas de gênero operam ao ordenar a corporificação de certos ideais de feminilidade e masculinidade, ideais que são quase sempre relacionados à idealização do vínculo heterossexual”.

Evidentemente, quando falamos de Linguística Queer estamos pisando em um campo de estudo ainda muito novo, embora promissor (BORBA, 2015), lugar onde se cruza a semântica, a pragmática, a performance e o discurso. 


\section{ANÁLISE DOS DADOS}

Linguisticamente falando, o uso do masculino foi designado pela tradição gramatical para referir-se de modo geral a um grupo de indivíduos compostos por pessoas do gênero masculino e gênero feminino, prevalecendo o masculino independentemente da quantidade existente no grupo. Caso exista um indivíduo do sexo masculino, prevalece o tratamento linguístico do masculino sobre o feminino. Deste modo, a cultura dominante (incluindo aqui a língua) exerce uma forma de coerção e violência sobre o sujeito, impondo determinados habitus sociais, linguísticos e simbólicos. Bourdieu (2003, p. 47) denomina esse processo de violência simbólica, entendida como:

\footnotetext{
Coerção que se institui por intermédio da adesão que o dominado não pode deixar de conceder ao dominante (e, portanto, à dominação) quando ele não dispõe, para pensá-la e para se pensar, ou melhor, para pensar, sua relação com ele [...] não sendo mais que uma forma incorporada da relação de dominação, fazem essa relação ser vista como natural, quando os esquemas que ele põe em ação para se ver e se avaliar, ou para ver e avaliar os dominantes (elevado/baixo, masculino/feminino, branco/negro, etc.) resultam da incorporação de classificações, assim naturalizadas, de que seu ser social é produto.
}

Tais esquemas linguísticos e cognitivos, construídos sócio historicamente, produzem efeitos de sentido que marginalizam o outro, colocando-o no lugar de dominado. Tais formas são produtos da vida social, no sentido pecheutiano, produzidos a partir de uma dada formação social e/ou formação ideológica.

No que se refere às questões de gênero, o patriarcado e a heteronormatividade constituída, são construções simbólicas que violentam os sujeitos à margem das categorias dominantes, neste caso, de macho sobre a fêmea, de masculino sobre o feminino, de heterossexualidade sobre as "sexualidades polimorfas" (FOUCAULT, 1984).

À vista disso, destacamos as materialidades abaixo:

Art. 25. Será objetivo permanente das autoridades responsáveis alcançar relação adequada entre o número de alunos e o professor, a carga horária e as condições materiais do estabelecimento (LDB n. 9.394/1996, grifos nossos).

Promover debates com a sociedade civil sobre o direito dos trabalhadores à assistência gratuita a seus filhos e dependentes em creches e pré-escolas (PNE, 2001, p.16, grifos nossos).

A gestão da educação e a cobrança de resultados, tanto das metas como dos objetivos propostos neste plano, envolverão comunidade, alunos, pais, professores e demais trabalhadores da educação. (PNE, 2001, p.21, grifos nossos). 
Além do direito da criança, a Constituição Federal estabelece o direito dos
trabalhadores, pais e responsáveis, à educação de seus filhos e dependentes
de zero a seis anos. Mas o argumento social é o que mais tem pesado na
expressão da demanda e no seu atendimento por parte do Poder Público. Ele
deriva das condições limitantes das famílias trabalhadoras, monoparentais,
nucleares, das de renda familiar insuficiente para prover os meios adequados
para o cuidado e educação de seus filhos pequenos e da impossibilidade de a
maioria dos pais adquirirem os conhecimentos sobre o processo de
desenvolvimento da criança que a pedagogia oferece (PNE, 2001, p. 08,
grifos nossos)

As materialidades acima citadas apontam para uma formação discursiva patriarcal, produzindo certo apagamento no que se refere às discussões de gênero. Os enunciados reproduzem a violência simbólica de gênero naturalizada na sociedade e tradicionalmente constituída a partir do uso do masculino sobre o feminino. Na LDB, por exemplo, os termos aluno e professor foram utilizados 35 e 12 vezes no masculino, respectivamente, utilizando-se $\mathrm{o}$ apagamento do feminino tanto nas formas singular como nas formas plural. $\mathrm{O}$ mesmo materializa-se no PNE (2001-2010), aluno (107 vezes), professores (92 vezes), trabalhadores (15 vezes). Observa-se o apagamento do gênero feminino, produzindo efeitos de sentido ligados a dominação masculina. No PNE (2011-2020) o termo aluno foi utilizado 05 vezes, sempre no plural. O mesmo acontece com o uso do vocábulo professor (18 vezes), 05 vezes no singular e 13 vezes plural.

Vale salientar que no PNE (2001-2010) o termo "trabalhadoras" foi utilizado apenas uma vez, entretanto não se refere às trabalhadoras da educação, tampouco às alunas que necessitam conciliar trabalho, educação e cuidado dos possíveis filhos. Deste modo, as materialidades produzem certo apagamento da diferença de gênero entre os trabalhadores e trabalhadoras da educação e, evidentemente, as especificidades sociais e biológicas de cada um, como a maternidade, o cuidado dos filhos, etc. No PNE (2011-2020) permanece esse apagamento. $\mathrm{O}$ vocábulo trabalhador foi utilizado 05 vezes, uma no singular e quatro no plural, não apresentando nenhuma discussão acerca da mulher/trabalhadora em educação.

Com relação às Diretrizes Curriculares Nacionais para a Educação Profissional Técnica de Nível Médio - DCNEPTNM , doravante Diretrizes Curriculares, vale fazer algumas observações. A primeira delas é que o termo aluno foi utilizado duas vezes, uma no singular e outra no plural, o vocábulo professor foi utilizado quatro vezes, apenas no plural. Em seguida, vale destacar que não há nenhuma menção ao gênero feminino quando se refere a profissionais da educação, tampouco ao alunado, alunos e alunas. Acontece o mesmo com termo trabalhador, utilizado no documento apenas uma vez (no plural) de maneira geral para 
designar homens e mulheres, trabalhadores e trabalhadoras. Isso reforça o que já foi mencionado sobre violência simbólica (BOURDIEU, 2003).

Isso nos leva a questionar o apagamento das diferenças de gênero, no que se refere às peculiaridades e papéis sociais de cada um, não materializa-se nas diretrizes a discussão sobre a maternidade, sobre o cuidado dos filhos, sobre as mulheres-mães estudantes, mulheres-mães trabalhadoras e mulheres-mães-estudantes trabalhadoras. Evidentemente, falar disso é ao mesmo tempo falar de condições de igualdade de acesso e permanência, falar de diferença de gênero, paradoxalmente, é falar de igualdade.

Por outro lado, vale salientar a construção de um discurso emergente acerca da igualdade de gênero, ainda no que se refere à análise da LDB. Entendemos a materialização de uma referência subentendida, encontrada nas entrelinhas do discurso. Sobre essa questão, destacamos a análise das materialidades abaixo:

Art. $3^{\circ} \mathrm{O}$ ensino será ministrado com base nos seguintes princípios:

I - igualdade de condições de acesso e permanência na escola; [...]

IV - respeito à liberdade e apreço à tolerância. (LDB n. 9.394/96, grifos nossos).

Art. $4^{\circ} \mathrm{O}$ dever do Estado com educação escolar pública será efetivado mediante a garantia de:

I - educação básica obrigatória e gratuita dos 4 (quatro) aos 17 (dezessete) anos de idade, organizada da seguinte forma:

a) pré-escola;

b) ensino fundamental;

c) ensino médio;

II - educação infantil gratuita às crianças de até 5 (cinco) anos de idade; [...]

$\mathrm{X}$ - vaga na escola pública de educação infantil ou de ensino fundamental

mais próxima de sua residência a toda criança a partir do dia em que completar 4 (quatro) anos de idade; (LDB n. 9.394/96, grifos nossos).

O Art. $3^{\circ}$ da LDB, no inciso I, coloca em evidência, embora não as delimite, as dificuldades de acesso e permanência na escola de alguns grupos específicos. A promoção da igualdade de acesso e permanência suscita uma discussão sobre gênero e os papéis sociais que homem e mulher exercem na sociedade, tais como trabalho, cuidado dos filhos, maternidade e paternidade, etc. nos leva a pensar também, que, independentemente desses papeis é dever do Estado garantir as condições de acesso e permanência a homens e mulheres e a diversas outras identidades de gênero que se colocam para além dos binarismos. O inciso IV, por sua vez, coloca o "respeito à liberdade" e à "tolerância" como um dos princípios da educação, produzindo efeitos de sentido ligados à dignidade da pessoa humana e respeito às diversas formas de identificação e identidade humana, no que se refere às preferências culturais, identidades sexuais e de gênero, diversidade étnica, religiosa, linguística etc. 
O Art. $4^{\circ}$, por sua vez, produz efeitos de sentido ligados à luta pela igualdade de gênero evidenciada nas décadas anteriores pelos movimentos sociais, principalmente o feminismo. Embora não seja evidente (pois o discurso não o é), as materialidades apontam para a maternidade e cuidado infantil, materializando as diferenças de gênero (homem/mulher) e a necessidade do Estado garantir condições de acesso às mulheres, mães-estudantes. Nesse sentido, a LDB reconhece a maternidade e a educação infantil e coloca a mulher no cenário educacional com a possibilidade de cuidar dos filhos e exercer suas atividades estudantis, tendo em vista o reconhecimento do direito da criança pequena à educação, o oferecimento de creches para as crianças até 05 (cinco) anos de idade e o direito da criança de estudar na escola mais próxima de sua residência. Por conseguinte, se produz, pelo menos em tese, a possibilidade de acesso e permanência das mulheres-mães na escola.

Conforme escreve Vianna e Unbehaum(2004, p. 93):

A integração da creche e da pré-escola no sistema educacional é fruto da luta do movimento de mulheres no Brasil que, nos anos de 1970, passou a incorporar uma série de demandas que visavam garantir a igualdade de oportunidades para as mulheres também na vida privada. É assim que o feminismo brasileiro vê contemplada na lei a proposta da creche como aparato educacional e a ampliação do direito à creche no local de trabalho também para os filhos de trabalhadores homens e para toda a faixa dos zero aos 6 anos. Nesse sentido, a LDB mantém uma conquista da própria Constituição de 1988, ao ampliar as definições legais de criança e de infância, tornando-se um marco na história da construção social desse novo sujeito de direitos: a criança pequena.

Da mesma forma, as DCNEPTNM também produzem efeitos de sentido materializados nas entrelinhas do discurso. Ao discorrer sobre a formulação de políticas públicas e finalidade da avaliação dos cursos, escreve-se que a divulgação dos resultados deve ser feita, dentre outras coisas, para:

IV - zelar pelo cumprimento das responsabilidades sociais das instituições mediante valorização de sua missão, afirmação da autonomia e da identidade institucional, atendimento às demandas socioeconômico-ambientais, promoção dos valores democráticos e respeito à diferença e à diversidade. (DCNEPTNM, 2012, s/p).

Os enunciados "valores democráticos" e "respeito à diferença e à diversidade" evocam para a Educação Profissional a promoção de políticas públicas que zelem pela responsabilidade das instituições de ensino. Zelo que está semanticamente e sintaticamente ligado aos valores democráticos e à diversidade. O enunciado "valores democráticos" ativam a memória discursiva retomando discursos acerca da dignidade da pessoa humana, da 
igualdade, da liberdade e do respeito à diferença. Por sua vez, o enunciado "respeito à diferença e à diversidade" coloca em evidência o respeito aos diversos grupos étnicos e minorias sociais (ou maiorias sociais desprestigiadas/marginalizadas), incluindo aqui, as diversas identidades de gênero à margem.

Dando continuidade à análise, trataremos da última forma de referência aos estudos de gênero, através da qual observamos um desvelamento no que se refere à discussão de gênero. Para tanto analisaremos alguns trechos do Plano Nacional da Educação, em que destacamos a meta 11 proposta para o Ensino Fundamental, um parágrafo do item 12 referente às diretrizes curriculares para o Ensino Fundamental e a meta 31 no tópico sobre Financiamento e Orçamento do Ensino Superior:

11. Manter e consolidar o programa de avaliação do livro didático criado pelo Ministério de Educação, estabelecendo entre seus critérios a adequada abordagem das questões de gênero e etnia e a eliminação de textos discriminatórios ou que reproduzam estereótipos acerca do papel da mulher, do negro e do índio. (PNE, 2001, p. 20, grifos nossos)

[..] As novas concepções pedagógicas, embasadas na ciência da educação, sinalizaram a reforma curricular expressa nos Parâmetros Curriculares Nacionais, que surgiram como importante proposta e eficiente orientação para os professores. Os temas estão vinculados ao cotidiano da maioria da população. Além do currículo composto pelas disciplinas tradicionais, propõem a inserção de temas transversais como ética, meio ambiente, pluralidade cultural, trabalho e consumo, entre outros. (PNE, 2001, p. 19 , grifos nossos)

31. Incluir, nas informações coletadas anualmente através do questionário anexo ao Exame Nacional de Cursos, questões relevantes para a formulação de políticas de gênero, tais como trancamento de matrícula ou abandono temporário dos cursos superiores motivados por gravidez e/ou exercício de funções domésticas relacionadas à guarda e educação dos filhos (PNE, 2001, p. 39, grifos nossos).

Pode-se observar nas materialidades citadas a preocupação do Ministério da Educação acerca dos critérios adotados no programa para avaliação do livro didático. Dentre as 30 orientações acerca do manual didático está presente o cuidado em evitar livros didáticos que reproduzam "estereótipos acerca do papel da mulher, do negro e do índio" colocam os estudos de gênero em evidência (PNE, 2001, p. 20). Ao introduzir a discussão sobre as diretrizes curriculares para o ensino fundamental, o PNE também orienta a discussão dos temas transversais já discutidos nos Parâmetros Curriculares Nacionais, tais como "ética, meio ambiente, pluralidade culturais, entre outros" (PNE, 2001, p. 19). 
Vale salientar que os Parâmetros Curriculares Nacionais - Temas Transversais dispõe de um capítulo inteiro discutindo sobre o tema "Orientação Sexual". Observa-se o desvelamento da discussão de gênero outrora apagada e camuflada. Nesse contexto, apresenta-se como um dos pilares pedagógicos que devem nortear a educação nacional, tanto no que se refere à organização pedagógica como administrativa e governamental, conforme pode ser observado na meta 31 supracitado que propõe a "formulação de políticas de gênero, tais como trancamento de matrícula ou abandono temporário dos cursos superiores motivados por gravidez e/ou exercício de funções domésticas relacionadas à guarda e educação dos filhos", que reconhece as diferenças de gênero, o papel social da mulher ligado à maternidade e ao cuidado dos filhos (PNE, 2001, p. 39).

Ainda sobre o desvelamento de sentidos, o PNE apresenta nas diretrizes para formação de professores a "h) inclusão das questões relativas à educação dos alunos com necessidades especiais e das questões de gênero e de etnia nos programas de formação". Deste modo, o PNE trata a discussão de gênero nas diversas facetas que envolvem o processo educacional, desde o currículo e temas transversais, a escolha do livro didático, formação de professores e políticas públicas de gênero que, em especial, envolvem o tratamento dado à mulher e aos diversos papéis sociais que ela exerce.

Outra questão bastante relevante no que se refere ao PNE e aos estudos de gênero é a relação entre a quantidade de alunos do sexo masculino e feminino. Ao tratar do acesso e permanência de meninos e meninas na escola, o PNE aponta que a distribuição das matrículas está equilibrada, apresentando um percentual de matrícula de $49,5 \%$ para o sexo feminino e 50, 5\% para o sexo masculino. Por outro lado, “esse equilíbrio sofre alterações na distribuição por sexo no decorrer dos anos, aspecto que não poderia ser desconsiderado do diagnóstico, [...] Essa desconsideração ignora o fracasso sistemático de meninos na educação básica, especialmente no ensino fundamental" (VIANNA; UNBEHAUM, 2004, p. 95).

Conforme escreve Carvalho (2000, p.142), "existe um problema crescente de acesso e permanência na escola para pessoas do sexo masculino", um problema de gênero que deve ser investigado. Sobre essa questão, Vianna e Unbehaum (2004, p. 95) escrevem

A tendência, bastante difundida por todo o país, de maior presença de crianças e adolescentes do sexo masculino nas séries iniciais - enquanto que as do sexo feminino concentram-se nas últimas séries - revela que o melhor desempenho das meninas percorre todo o ensino fundamental, visto que desde os 7 anos, o índice de defasagem entre idade e série escolar é maior para os meninos $(14,7 \%)$ do que para as meninas (13\%). Os meninos são a maioria $(53,2 \%)$ na $1^{\text {a }}$ série, mas a partir da $4^{\text {as }}$ série a repetência entre os meninos é maior do que entre as meninas e, nas $8^{\text {as }}$ séries, $55 \%$ dos alunos são do sexo feminino. 
Isso se deve, talvez, à naturalização do trabalho masculino, mesmo na adolescência. Ao contrário das meninas, muitos garotos são obrigados a ajudar os pais com a renda da família com trabalho informal. Isso pode também estar associado ao uso de drogas que na sua maioria atinge os homens, incluindo também crianças e adolescentes. Evidentemente, é uma questão que merece uma atenção maior.

Por sua vez, o PNE (2011-2020) materializa certo desvelamento, trazendo as concepções de identidade de gênero. Na meta 03 acerca da universalização do ensino, no tópico 3.9 registra-se a seguinte estratégia: "Implementar políticas de prevenção à evasão motivada por preconceito e discriminação à orientação sexual ou à identidade de gênero, criando rede de proteção contra formas associadas de exclusão". Desse modo, o PNE reconhece os processos de exclusão e marginalização da pessoa LGBT, suscitando a necessidade de produção de estratégias que combatam o preconceito. O PNE (2011-2020), embora sucinto, evidencia o respeito à diversidade e à equidade. No art. $2^{\circ}$ onde são apresentadas as suas diretrizes, no inciso X, escreve-se como fundamento a "difusão dos princípios da equidade, do respeito à diversidade e a gestão democrática da educação". Difusão essa que produz efeitos de sentido ligados à produção do conhecimento acerca da equidade e diversidade, dando espaço para uma infinidade de possibilidades dentro da práxis pedagógica, no que tange ao ensino e ao respeito às diferenças.

\section{CONSIDERAÇÕES FINAIS}

O tratamento dado à discussão de gênero nos documentos oficiais analisados aponta para um breve apagamento do assunto na Lei de Diretrizes e Bases da Educação Nacional LDB (1996). Pode-se também constatar que o artigo $3^{\circ}$ e o artigo $4^{\circ}$ da LDB produzem efeitos de sentido que também podem estar associados às questões de gênero, principalmente no que se refere aos princípios da educação nacional previstos no artigo $3^{\circ}$, tais como a igualdade de acesso e permanência, respeito e tolerância. Por sua vez, o artigo $4^{\circ}$ nos remete ao reconhecimento da maternidade e ao reconhecimento das diferenças de gênero concernentes aos papéis sociais da mulher e a luta feminista em prol da Educação Infantil.

Ao contrário da LDB, o Plano Nacional de Educação - PNE, decênio 2001-2010, apresenta uma discussão bem mais elaborada acerca da diversidade de gênero e educação sexual, apresentando orientações acerca da escolha do livro didático, da formação de professores e de políticas de gênero que leve em consideração os papéis sociais da mulher na sociedade, tais como o cuidado dos filhos e a maternidade. O PNE traz à baila a discussão 
sobre a inclusão relativa às questões de gênero, além de postular a necessidade de discussão dos temas transversais, dentre eles, a Orientação Sexual.

Por sua vez, PNE (2011-2020) apresenta a noção de identidade de gênero, conceito utilizado pela primeira vez em documentos oficiais da educação. Embora seja um documento sucinto, o PNE traz algumas breves observações sobre equidade, diversidade e combate ao preconceito motivado pela diferença de gênero que, segundo o próprio documento, pode levar à evasão escolar.

Com base na análise realizada, constatamos uma evolução no que se refere a discussão de gênero e a produção de efeitos de sentido que desnaturalizam o patriarcado e a heterossexualidade normativa, historicamente construída. Os documentos apontam para um avanço que vai do apagamento da discussão sobre gênero na LDB de 1996 para o aprimoramento da discussão no Plano Nacional de Educação - PNE, tanto no decênio 2001 a 2010, como no decênio 2011 a 2020.

\section{Referências:}

BORBA, R. Linguística Queer: uma perspectiva pós-identitária para os estudos da linguagem. Revista Entrelinhas -Vol. 9, n. 1, jan./jun. 2015.

BOURDIEU, Pierre. A dominação masculina. Rio de janeiro: Bertrand Brasil, 2003.

BRASIL. Lei n. ${ }^{\circ} 9.394$ de 20 de dezembro de 1996. Estabelece as diretrizes e bases da educação nacional. Disponível em: $<$ http://www.planalto.gov.br/ccivil 03/Leis/L9394.htm>. Acesso em 10 de março de 2019.

Plano Nacional da Educação (2001-2010). Disponível em:< http://portal.mec.gov.br/arquivos/pdf/L10172.pdf> . Acesso em 10 de março de 2019.

Plano Nacional da Educação (2011-2020). Disponível em:< http://portal.mec.gov.br/index.php?option=com_docman\&view=download\&alias=7116-pl-pn e-2011-2020\&Itemid=30192 > . Acesso em 10 de março de 2019.

BUTLER, Judith. 2003b. Critically Queer. In: Erin Striff (ed.). Performance Studies. New York, Palgrave, p152-177.

FOUCAULT, M. Microfísica do poder . 4 ed. Rio de Janeiro, Graal, 1984.

KATZ, J. A Invenção da heterossexualidade. Rio de Janeiro: Ediouro, 1996.

MOTSCHENBACHER, H. 2011. Taking queer linguistics further: sociolinguistics and critical heteronormativity research. International Journal of the Sociology of Language 212:149-179. 
ORLANDI, Eni. Análise de discurso: princípios e procedimentos. 4 ed. Campinas: Pontes, 2002.

. A Análise de Discurso em suas diferentes tradições intelectuais: o Brasil. In:

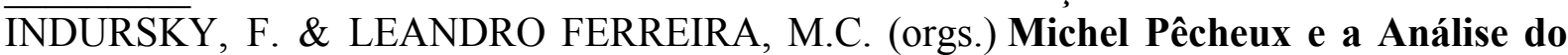
Discurso: uma relação de nunca acabar. São Carlos: Claraluz, 2005, p. 75 - 88.

PÊCHEUX, M.; FUCHS, C. A propósito da Análise Automática do Discurso: atualização e perspectivas (1975). In: GADET, F. \& HAK, T. A propósito da análise automática do discurso: atualizações e perspectivas. Trad. Bethania S. Mariani et al. 2.ed., Campinas, SP: UNICAMP, 1997.

. Semântica e discurso: uma crítica à afirmação do óbvio. 2 ed, Campinas: Ed. da UNICAMP, 1995.

VIANNA, Cláudia Pereira; UNBEHAUMO, Sandra. GÊNERO NAS POLÍTICAS PÚBLICAS DE EDUCAÇÃO NO BRASIL: 1988-2002. Cadernos de Pesquisa, v. 34, n. 121, jan./abr. 2004. Disponível em:< http://publicacoes.fcc.org.br/ojs/index.php/cp/article/view/490/494>. Acesso em 17 de setembro de 2018.

Compocs, v1, n 23 - jul -dez 2020 